\title{
Activation of Orbital and Medial Prefrontal Cortex by Methylphenidate in Cocaine-Addicted Subjects But Not in Controls: Relevance to Addiction
}

\author{
Nora D. Volkow, ${ }^{1,2}$ Gene-Jack Wang, ${ }^{3}$ Yeming Ma, ${ }^{2}$ Joanna S. Fowler, ${ }^{3}$ Christopher Wong, ${ }^{3}$ Yu-Shin Ding, ${ }^{3}$ \\ Robert Hitzemann, ${ }^{4}$ James M. Swanson, ${ }^{5}$ and Peter Kalivas ${ }^{6}$ \\ ${ }^{1}$ National Institute of Drug Abuse and ${ }^{2}$ National Institute of Alcohol Abuse and Alcoholism, Rockville, Maryland 20857, ${ }^{3}$ Medical and Chemistry \\ Departments, Brookhaven National Laboratory, Upton, New York 11973, ${ }^{4}$ Department of Behavioral Neuroscience, Oregon Health and Science University, \\ Portland, Oregon 97201, ${ }^{5}$ Child Development Center, University of California at Irvine, Irvine, California 92612, and ${ }^{6}$ Department of Neurosciences, Medical \\ University of South Carolina, Charleston, South Carolina 29465
}

Drugs of abuse are rewarding to addicted and nonaddicted subjects, but they trigger craving and compulsive intake only in addicted subjects. Here, we used positron emission tomography (PET) and $\left[{ }^{18} \mathrm{~F}\right]$ deoxyglucose to compare the brain metabolic responses (marker of brain function) of cocaine-addicted subjects $(n=21)$ and controls $(n=15)$ to identify brain regions that are uniquely activated in addicted subjects by intravenous methylphenidate (a drug that cocaine-addicted subjects report to be similar to cocaine). In parallel, we also measured the changes in dopamine (DA) induced by intravenous methylphenidate (using PET and [ $\left.{ }^{11} \mathrm{C}\right]$ raclopride) in the striatum and in the thalamus. Metabolic responses between groups differed significantly only in the right medial orbital prefrontal cortex [Brodmann's area (BA) 25 and medial BA 11], where methylphenidate increased metabolism in addicted subjects but decreased metabolism in controls. These changes were associated in all subjects with increased "desire for methylphenidate" and in the addicted subjects with "cocaine craving." In addicted subjects, increases in BA 25 were also associated with mood elevation. Methylphenidate-induced increases in metabolism in the medial orbital prefrontal cortex were associated with its increase of DA in the thalamus but not in the striatum. These findings provide evidence that enhanced sensitivity of BA 25 (region involved with emotional reactivity) and BA 11 (region involved with salience attribution and motivation) in cocaine-addicted subjects may underlie the strong emotional response to the drug and the intense desire to procure it that results in craving and compulsive drug intake. It also suggests that the mesothalamic DA pathway may contribute to these processes.

Key words: thalamus; dopamine; motivation; orbitofrontal; cingulate gyrus; imaging

\section{Introduction}

The ability of cocaine to increase dopamine (DA) in the nucleus accumbens (NAc) seems to be crucial for the reinforcing effects of cocaine (Koob and Bloom, 1988). However, cocaine-induced DA increases in the NAc do not explain addiction, because this effect occurs in nonaddicted as well as addicted subjects (Volkow et al., 1997a). A reasonable hypothesis is that addiction results from adaptations triggered by intermittent cocaine-induced supraphysiological perturbations of the DA system, which could disrupt the circuits regulated by DA. Indeed, positron emission tomography (PET) reveals that DA brain function (assessed by $\mathrm{DA} \mathrm{D}_{2}$ receptors and DA release in the striatum), as well as activity in the orbitofrontal cortex (OFC) and anterior cingulate gyrus (CG) (assessed by brain glucose metabolism), is markedly de-

Received Nov. 26, 2004; revised March 7, 2005; accepted March 7, 2005.

This work was supported in part by Department of Energy (Office of Biological and Environmental Research) Grant DE-AC02-98CH10886 and National Institute on Drug Abuse Grant R01DA06891.

Correspondence should be addressed to Dr. Nora D. Volkow, National Institute of Drug Abuse, 6001 Executive Boulevard, Room 5274, Rockville, MD 20857.E-mail: nvolkow@nida.nih.gov.

D0I:10.1523/JNEUROSCI.0433-05.2005

Copyright $\odot 2005$ Society for Neuroscience $\quad$ 0270-6474/05/253932-08\$15.00/0 creased in cocaine-addicted subjects tested during withdrawal (Volkow et al., 1993). Reductions in OFC and CG metabolism were associated with decreases in striatal $\mathrm{DA}_{2}$ receptors, which suggested that these cortical changes reflect the consequences of disrupted DA activity. From these studies, a hypothesis emerged that abnormalities in the OFC and CG, which are regions involved with salience attribution and inhibitory control and implicated in compulsive behaviors, underlie craving and compulsive drug intake in addiction (Volkow and Fowler, 2000). This hypothesis was evaluated in this study by comparing the regional brain metabolic responses of cocaine-addicted subjects with controls after administration of the stimulant drug methylphenidate (MP). In parallel, we also measured the association between the metabolic changes and the DA changes induced by MP to assess whether the brain responses were linked to its dopaminergic effects.

For this purpose, detoxified cocaine-addicted subjects and controls were administered two sequential doses of intravenous MP. PET imaging of $\left[{ }^{18} \mathrm{~F}\right]$ deoxyglucose (FDG) was used to measure the effects of MP in brain glucose metabolism (marker of brain function) (Sokoloff et al., 1977), and imaging of $\left[{ }^{11} \mathrm{C}\right] \mathrm{ra}-$ 
clopride was used to measure DA transmission (Volkow et al., 1994). We selected MP because it is similar pharmacologically to cocaine; both drugs increase DA by blocking DA transporters (DATs) with similar potencies (Volkow et al., 1995) and induce similar changes in regional brain activation (Dirckx et al., 2004). Moreover, cocaine-addicted subjects report that intravenous MP has similar effects to cocaine (Wang et al., 1997). We chose two sequential doses rather than a single dose because this mimics better the pattern of drug intake in cocaine abuse (multiple administrations). Previous publications have documented the effects of MP on brain metabolism in controls (Volkow et al., 1997b) and in cocaine-addicted subjects (Volkow et al., 1999) and have compared DA changes between controls and addicted subjects (Volkow et al., 1997a). Here, we compare for the first time the brain metabolic responses to MP between cocaineaddicted subjects and controls and evaluate the association between MP-induced metabolic and DA changes. We hypothesized that responses to MP of addicted subjects and controls would differ in the OFC and CG and that these differences would be associated with the "desire for the drug" and would be linked to the dopaminergic effects of MP.

\section{Materials and Methods}

Subjects. The cocaine-addicted subjects were 21 male right-handed subjects [age, $36 \pm 5$ years; education, $12 \pm 2$ years; intelligence quotient (IQ)-verbal, $103 \pm 11$ ] who were inpatients at Veterans Administration Hospital (Northport, NY). Subjects fulfilled Diagnostic and Statistical Manual of Mental Disorders, fourth revision (DSM-IV) criteria for cocaine dependence and had used cocaine (free-base or as crack) for at least the previous 6 months (at least " 3 g" per week). Note that subjects were excluded who met DSM-IV criteria for cocaine abuse rather than dependence. The exclusion criteria were current or past psychiatric disease other than cocaine dependence; past or present history of neurological, cardiovascular, or endocrinological disease; history of head trauma leading to loss of consciousness $>30 \mathrm{~min}$; and current medical illness and dependence or abuse on any substance other than cocaine, nicotine, or caffeine. Care was taken to exclude subjects that abused or were addicted to alcohol or drugs other than cocaine and nicotine. Subjects were tested within 1 month of their last cocaine use $(14 \pm 7 \mathrm{~d})$ and had an average history of $13 \pm 5$ years of cocaine use. Controls were 15 healthy righthanded male subjects (age, $35 \pm 7$ years; education, $15 \pm 2$ years; IQverbal, $115 \pm 12$ ), and although they had previous experience with recreational drug use, they were excluded if they met DSM-IV criteria for alcohol or drug abuse or dependence. The exclusion criteria were as for the addicted subjects, except for cocaine dependence. Cocaine-addicted subjects remained in the hospital after completion of the study and were not discharged unless craving for cocaine had subsided. The protocol was approved by the Institutional Review Boards at Veterans Administration Hospital and at Brookhaven National Laboratory. Written informed consent was obtained after complete description of the study to the subjects.

Scans. Each subject underwent two PET FDG and two PET $\left[{ }^{11} \mathrm{C}\right] \mathrm{ra}-$ clopride scans done on two separate days. On a given day, each subject was given an injection first of $\left[{ }^{11} \mathrm{C}\right]$ raclopride and then 90 min later an injection of FDG. Before each radiotracer injection, the subjects were given injections of a placebo ( $3 \mathrm{cc}$ of saline intravenously before $\left[{ }^{11} \mathrm{C}\right] \mathrm{ra}-$ clopride and $3 \mathrm{cc}$ of saline intravenously before FDG) on the first day and injections of MP $\left(0.5 \mathrm{mg} / \mathrm{kg}\right.$ MP intravenously before $\left[{ }^{11} \mathrm{C}\right]$ raclopride and $0.25 \mathrm{mg} / \mathrm{kg}$ MP intravenously before FDG) on the second day (Fig. 1). The order of administration was fixed (placebo was given on the first day, and MP was given on the second day) to avoid possible long-lasting effects of MP on brain metabolism. The study was a single blind design (subjects were blind to the drugs received). For $\left[{ }^{11} \mathrm{C}\right]$ raclopride, dynamic scans were started immediately after injection of $4-10 \mathrm{mCi}$ of $\left[{ }^{11} \mathrm{C}\right] \mathrm{ra}-$ clopride (specific activity, $0.5-1.5 \mathrm{Ci} / \mu \mathrm{M}$ at end of bombardment) for a total of 60 min using procedures published previously (Volkow et al., 1994). For FDG, an emission scan was obtained for $20 \mathrm{~min}$ and was

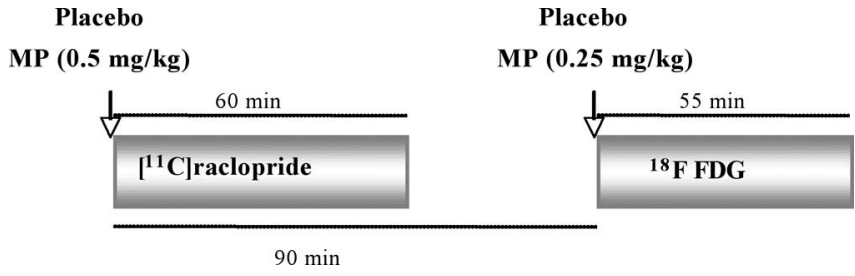

Figure 1. Diagram of experimental design. Subjects were tested on two separate days. On each day, they were scanned first with $\left[{ }^{11} \mathrm{C}\right]$ raclopride, and this was followed by an FDG scan. On the first day of the study, subjects received intravenous placebo before each radiotracer injection, and on the second day, they received intravenous MP before each radiotracer injection.

started 35 min after injection of 4-6 mCi of FDG on a CTI 931 tomograph $(6.5 \times 5.9 \times 5.9 \mathrm{~mm}$ full-width at half-maximum; 15 slices $)$ using procedures described previously (Wang et al., 1993). FDG measures were completed in all subjects, but the $\left[{ }^{11} \mathrm{C}\right]$ raclopride scans in one of the controls and in two of the cocaine-addicted subjects were lost because of technical errors.

Behavioral measures. Before and at $27 \mathrm{~min}$ after the first and the second MP (or placebo) dose, subjects rated drug effects (high, desire for MP, desire for cocaine, restlessness, and mood) on a $0-10$ analog scale (Wang et al., 1997). When asked about the "desire for MP" subjects were asked to rate the desire to have the drug that they had just received (placebo or MP). MP concentration in plasma was measured using capillary gas chromatography/mass spectroscopy (Srinivas et al., 1991). A factorial repeated ANOVA was used to assess the effects of MP in the behavioral measures (drug main effect) and to assess whether the differences differed between controls and addicted subjects (drug by group interaction effect).

Analysis. The data for the metabolic images were analyzed using Statistical Parametric Mapping (SPM) (Friston et al., 1995), and the results were corroborated with region of interest (ROI) analysis. For the SPM analyses, the images were spatially normalized using the template provided in the SPM 99 package, then normalized to the mean metabolic activity for the entire brain (mean of all voxels within the brain) and subsequently smoothed with a $16 \mathrm{~mm}$ isotropic Gaussian kernel. Pairedsamples $t$ tests were performed to compare the images obtained in the placebo and MP conditions separately for the addicted subjects and the controls. Independent (unpaired) $t$ tests were used to compare the difference images (placebo - MP) for the cocaine-addicted and control groups. Significance was set at $p<0.005$ for clusters $\geq 100$ voxels. The statistical maps were overlaid on a magnetic resonance imaging (MRI) structural image

For the ROI analyses, an automated ROI extraction method was used based on the standard brain template of the Talairach atlas (Talairach and Tournoux, 1988). First, to eliminate variations across the brain of individuals, the PET FDG images were mapped into the Talairach brain using the spatial normalization package provided in SPM. The inverse mapping procedure was used to extract the Talairach coordinates of all voxels for a given anatomical region using the stereotaxic coordinates provided in the Talairach Daemon database (Collins et al., 1995; Lancaster et al., 1997, 2000). These anatomically defined ROI were overlapped voxel by voxel onto the normalized PET image (Volkow et al., 2002). This automated ROI method was validated by comparing the metabolic measures obtained with the manually drawn ROI and those obtained with the automated ROI from FDG images of 35 subjects (Ma et al., 2004). The correlations between the two methods were very high and ranged between $r=0.86$ for head of caudate and $r=0.99$ for the middle temporal gyrus. A factorial repeated ANOVA was used to assess the effects of MP in the metabolic measures (drug effect) and to assess whether the differences differed between controls and addicted subjects (drug by group interaction effect). Because controls and cocaine-addicted subjects differed in years of education and on their IQ scores, we performed a covariance analysis to assess whether these differences influenced the results.

For the $\left[{ }^{11} \mathrm{C}\right]$ raclopride images, we obtained ROI in the striatum, thalamus, and cerebellum, from which we generated time-activity curves 
as described previously (Volkow et al., 1994). The time-activity curves for tissue concentration and unchanged tracer in plasma were used to calculate the distribution volumes (DVs), using a graphical analysis technique for reversible systems (Logan et al., 1990), to estimate the equilibrium ratio of tissue concentration to plasma concentration in the striatum, thalamus, and cerebellum. The ratios of DVs in the striatum and in the thalamus to those in the cerebellum correspond to $\left(B_{\text {max }} / K_{\mathrm{d}}\right)+1$ and are insensitive to changes in cerebral blood flow (Logan et al., 1994). The response to MP was quantified as the percentage of change in $B_{\text {max }} / K_{\mathrm{d}}$ from placebo $\left(B_{\max } / K_{\mathrm{dPlacebo}}-B_{\max } / K_{\mathrm{dMP}} /\right.$ $\left.B_{\text {max }} / K_{\text {dPlacebo }} \times 100\right)$.

Pearson product moment correlations were used to assess the association between the regional metabolic changes induced by MP (expressed as the percentage of change from the metabolic measures obtained after placebo), which differed between controls and addicted subjects, and the changes in behavioral ratings induced by MP (difference between an individual's highest scores obtained during MP administration and the scores before MP administration). Correlations between the metabolic and behavioral measures were based on data from all subjects, except for the behavioral measure of cocaine craving when correlations were from just the cocaine abusers, because they were the only ones that experienced significant drug craving with MP. We also report the correlations with desire for MP and for "mood" separately for the cocaine abusers. In addition, correlations were obtained between the changes in DA (percentage of change in $B_{\max } / K_{\mathrm{d}}$ ) and changes in metabolic activity for regions where the response differed between controls and addicted subjects.

\section{Results}

\section{Behavioral effects of MP}

MP induced significant changes in the behavioral measures in both groups of subjects for self-reports of "high" (ANOVA; drug effect; $F=50 ; p<0.0001)$, desire for MP $(F=39 ; p<0.0001)$, and "restlessness" $(F=30 ; p<0.0001)$ (Table 1). The behavioral effects differed between the groups; in controls, MP induced significantly greater increases in self-reports of high (ANOVA; interaction effect; $F=6.3 ; p<0.003)$ and restlessness $(F=4.6 ; p<$ $0.05)$ than in cocaine-addicted subjects, but MP-induced increases in desire for MP $(F=3.8 ; p<0.05)$ was greater in the addicted subjects than in controls (Table 1$)$. In addition, in cocaine abusers, MP increased "cocaine craving" ( $p<0.001)$. Neither serum concentrations of MP nor cardiovascular effects differed between the groups (data not shown).

\section{Effects of MP on regional brain metabolism}

The SPM analysis conducted separately for each group revealed significant relative metabolic increases with MP in the cerebellum and occipital cortex and relative metabolic decreases in the caudate and temporal insula, both in controls and in addicted subjects (Fig. 2). In addition, in controls, MP increased metabolism in the precuneus and left thalamus and decreased metabolism in the NAc and in the right orbital and medial prefrontal cortices (including BA 25 and medial BA 11). Table 2 provides the Talairach coordinates for the regions that were significantly affected by MP in controls. In contrast, in cocaine-addicted subjects, MP increased metabolism in the right orbital medial prefrontal cortex (OMPFC) and decreased metabolism in the right frontal cortex (BA 8, BA 6, and BA 4) and parietal cortex (BA 40) (Fig. 1). Table 3 provides the Talairach coordinates of the regions that were significantly affected by MP in cocaine-addicted subjects.
Regional brain metabolic differences in response to MP between controls and addicted subjects

The SPM analysis of the difference image (placebo - MP) revealed that only two brain regions differed significantly at $p<$ 0.005 between controls and addicted subjects: an area in the right OMPFC [as defined by Ongur and Price (2000)] that included BA 25 and middle BA 11 and an area in the left occipital gyrus (BA 19) (Fig. 3A, Table 4).

The ROI comparison of the response to MP corroborated that the response to MP in the OMPFC differed between the groups (ANOVA; interaction effect; $F=31 ; p<0.0001$ ) but did not corroborate the differences in BA 19. The difference in the right OMPFC remained significant after covarying for years of education (ANCOVA; $p<0.0001$ ) or for IQ $(p<0.0001)$. MP significantly increased metabolism in the right OMPFC $(p<0.05)$, whereas in controls it decreased metabolism $(p<0.0005)$ (Fig. $3 B$ ). Separate analysis for subregions revealed that the differences were significant both for right BA $25(p<0.0003)$ and for right BA $11(p<0.01)$. At baseline (placebo scan), metabolism in the right OMPFC was also significantly lower in cocaine-addicted subjects than in controls $(F=22 ; 1.1 \pm .09$ vs $1.24 \pm .09 ; p<$ $0.0001)$.

\section{Correlations between brain metabolism and behavior}

Correlations were significant between the changes in metabolism in right BA 25 and desire for MP (all subjects, $r=0.55, p<$ 0.0005 ; addicted subjects, $r=0.46, p<0.05$; control subjects, $r=$ 0.25 , NS) (Fig. 3C) and for "desire for cocaine" (all subjects, $r=$ $0.50, p<0.002$; addicted subjects, $r=0.50, p<0.02$; control subjects, $r=0.07, \mathrm{NS})$. The correlations with changes in right BA 11 and desire for cocaine were not significant (all subjects, $r=$ 0.32, $p=0.06$; addicted subjects, $r=0.31, p=0.17$; control subjects, $r=0.05$, NS). The correlations between changes in right BA 11 and desire for MP were not significant (all subjects, $r=$ $0.27, p=0.11$; addicted subjects, $r=0.17$, NS; control subjects, $r=0.02$, NS). In addition, in cocaine abusers only but not in controls, changes in metabolism in BA 25 were associated with MP-induced changes in self-reports of $\operatorname{mood}(r=0.52 ; p<0.02)$; the greater the increases in BA 25, the higher the increases in ratings of mood.

\section{Effects of MP on [ $\left.{ }^{11} \mathrm{C}\right]$ raclopride binding and correlations with MP-induced change in metabolism}

MP significantly decreased $B_{\max } / K_{\mathrm{d}}$ (measure of receptor availability) in the striatum in both controls (placebo, $2.86 \pm 0.28$; MP, $2.22 \pm 0.38$ ) and cocaine-addicted subjects (placebo, $2.61 \pm$ 0.39; MP, $2.34 \pm 0.41$; ANOVA; drug effect; $F=27 ; p<0.0001$ ). Baseline measures of $B_{\max } / K_{\mathrm{d}}$ in the striatum were smaller in addicted subjects than in controls in the striatum (control subjects, $2.90 \pm 0.34$; addicted subjects, $2.59 \pm 0.34 ; F=4.1 ; p<$ 


\section{Controls}
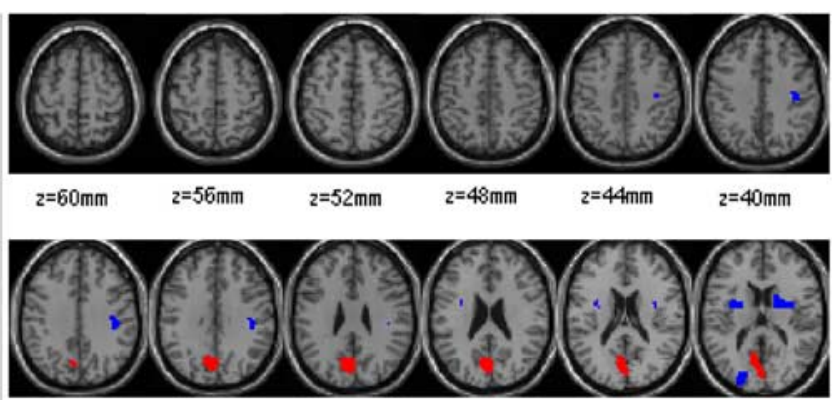

$z=36 \mathrm{~mm}$

$2=32 \mathrm{~mm}$

$2=28 \mathrm{~mm}$

$2=24 \mathrm{~mm}$

$z=20 \mathrm{~mm}$

$z=16 \mathrm{~mm}$

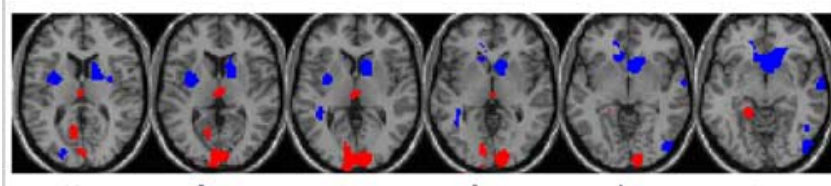

$z=12 \mathrm{~mm} \quad z=8 \mathrm{~mm}$

$2=4 \mathrm{~mm}$

$z=0 \mathrm{~mm}$

$z=-4 \mathrm{~mm}$

$2=-8 \mathrm{~mm}$

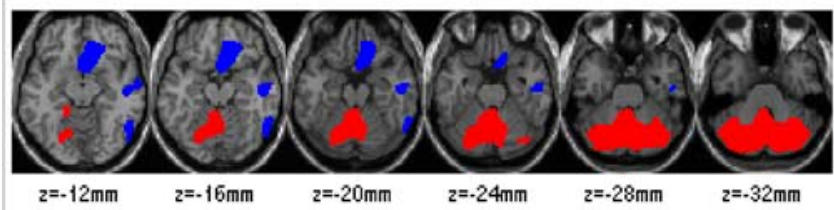

\section{Cocaine Abusers}
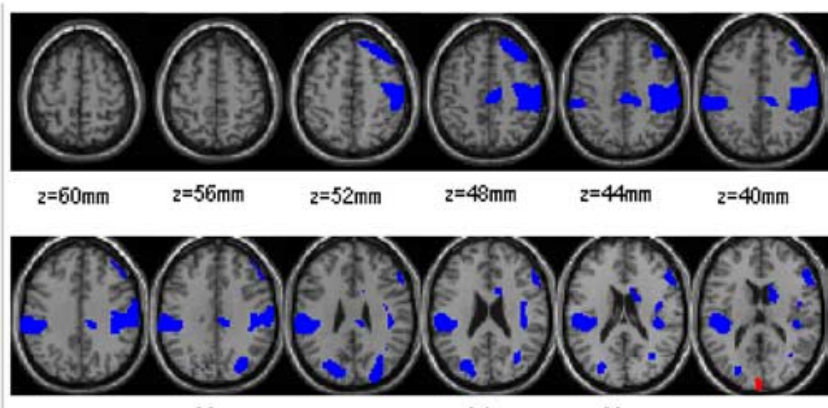

$z=36 \mathrm{~mm} \quad z=32 \mathrm{~mm} \quad z=28 \mathrm{~mm} \quad z=24 \mathrm{~mm} \quad z=20 \mathrm{~mm} \quad z=16 \mathrm{~mm}$

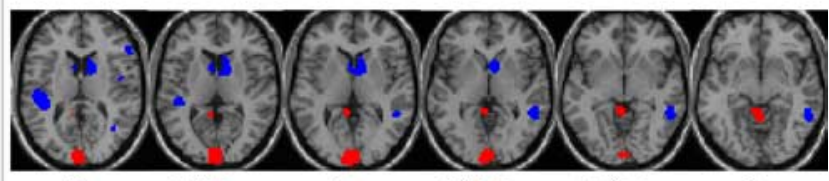

$z=12 \mathrm{~mm} \quad z=8 \mathrm{~mm} \quad z=4 \mathrm{~mm} \quad z=0 \mathrm{~mm} \quad z=.4 \mathrm{~mm} \quad z=.8 \mathrm{~mm}$

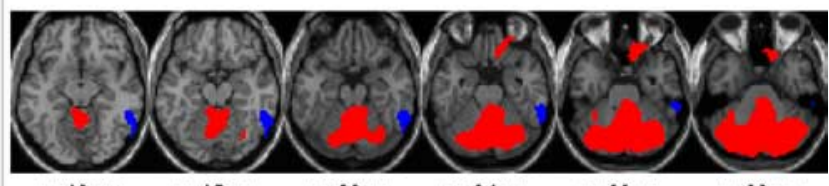

$z=-12 \mathrm{~mm} \quad z=-16 \mathrm{~mm}$

$=.20 \mathrm{~mm}$

$2=-24 m m$

$2=-32 \mathrm{~mm}$

Figure 2. Brain regions where MP significantly $(p<0.005)$ increased (red) or decreased (blue) metabolism in controls and in cocaine-addicted subjects are shown.

Table 2. Location of regions where metabolism was increased or decreased significantly by MP in controls subjects ( $p<0.005$; volume, $\geq 100$ voxels)

\begin{tabular}{llrrrr}
\hline Region & Hemisphere & BA & $x$ & $y$ & $z$ \\
\hline Increases & & & & & 4 \\
Occipital & Right & 18 & 1 & -93 & 5 \\
& Left & & -1 & -93 & -28 \\
$\quad$ Cerebellum & Right & & 1 & -65 & -21 \\
& Left & & -1 & -65 & 27 \\
Precuneus & Left & 31 & -5 & -63 & 8 \\
Thalamus & Left & & -1 & -2 & \\
Decreases & & & & & 8 \\
$\quad$ Caudate head & Right & & 10 & 15 & -1 \\
Temporal insula & Left & & -4 & -1 & 11 \\
NAc & Right & & 5 & 10 & -8 \\
Frontal medial & Right & 11,25 & 7 & 27 & 11 \\
\hline
\end{tabular}

$0.05)$ but did not differ in the thalamus (control subjects, $0.42 \pm$ 0.10 ; addicted subjects, $0.43 \pm 0.15 ; F=1.9 ; p=0.17$ ). The responses in the striatum differed between the groups (ANOVA; interaction effect; $F=5.1 ; p<0.05$ ), indicating that the decrements were significantly smaller in addicted subjects $(-10 \pm$ $14 \%$ change) than in controls $(-21 \pm 16 \%$ change $)$. In the thalamus, MP significantly changed $B_{\max } / K_{\mathrm{d}}$ (ANOVA; drug effect; $F=5.2 ; p<0.05)$, and the response also differed between groups (ANOVA; interaction effect; $F=10 ; p<0.004$ ). In addicted subjects but not in controls, MP significantly decreased $B_{\max } / K_{\mathrm{d}}$ in the thalamus (control subjects, $16 \pm 34 \%$ change; cocaineaddicted subjects, $-35 \pm 36 \%$ change). The correlation between MP-induced changes in $B_{\text {max }} / K_{\mathrm{d}}$ and the changes in metabolism in the right OMPFC were significant in the thalamus $(r=0.49$; $p<0.005$ ) (Fig. 4). The correlations with MP-induced changes in DA in the striatum were not significant (data not shown).
Table 3. Location of regions where metabolism was increased or decreased significantly by MP in cocaine-addicted subjects ( $p<0.005$; volume $\geq 100$ voxels)

\begin{tabular}{llrrrr}
\hline Region & Hemisphere & BA & $x$ & $y$ & $z$ \\
\hline Increases & & & & & \\
$\quad$ Cccipital & Left & 18 & -3 & -95 & 7 \\
$\quad$ Cerebellum & Right & & 1 & -77 & -25 \\
& Left & & -1 & -77 & -25 \\
$\quad$ Frontal medial & Right & 11 & 11 & 37 & -25 \\
Decreases & & & & & \\
$\quad$ Caudate head & Right & & 5 & 10 & 8 \\
$\quad$ Temporal superior & Left & 22 & -47 & -30 & -12 \\
Frontal paracentralis & Right & 4,6 & 45 & -15 & 44 \\
& Left & & -47 & -17 & 40 \\
Frontal superior & Right & 8 & 30 & 35 & 48 \\
Parietal inferior & Right & 40 & 55 & -30 & 36 \\
& Left & & -59 & -33 & 37 \\
Occipital gyrus & Right & 19 & 20 & -85 & 28 \\
& Left & & -25 & -85 & 28 \\
\hline & & & & &
\end{tabular}

\section{Discussion}

The main difference in the brain metabolic response to MP between the control and cocaine-addicted groups was in an area in the right OMPFC that included BA 25 (ventral region in the anterior CG) and medial BA 11 (medial region in the OFC). The qualitative difference in the response (in controls it decreased metabolism, and in cocaine-addicted subjects it increased metabolism) provides additional evidence of the involvement of the anterior CG and the OFC in cocaine addiction. Abnormalities in the OFC and anterior CG have been reported previously in cocaine-addicted (Modell et al., 1990; Volkow et al., 1991, 1993; Franklin et al., 2002; Bolla et al., 2003; Matochik et al., 2003; Myrick et al., 2004), methamphetamine-addicted (Volkow et al., 2001; Sekine et al., 2003), heroin-addicted (Sell et al., 2000), and marijuana-addicted (Volkow et al., 1996) subjects and in alcohol- 
ics (Modell et al., 1990; Volkow et al., 1997c; Dao-Castellana et al., 1998; Myrick et al., 2004), suggesting that they reflect a common abnormality across various types of drug addictions.

\section{Previous functional neuroimaging} studies in cocaine abusers

Imaging studies have compared the response of cocaine abusers and controls to cocaine-related stimuli and to nondrug reinforcers. When presented with stimuli that are associated with cocaine (video of cocaine administration, imagery of previous drug experiences), various brain regions are activated in cocaine abusers, including the anterior CG (Maas et al., 1998; Childress et al., 1999; Garavan et al., 2000; Kilts et al., 2001; Wexler et al., 2001; Bonson et al., 2002) and OFC (Grant et al., 1996; Wang et al., 1999). In contrast, when cocaine abusers were exposed to nondrug reinforcers (i.e., erotic stimuli), they showed a blunted activation, compared with controls, in regions that are activated by cocaine cues (including anterior CG and medial frontal regions) (Garavan et al., 2000). This suggests that in the addicted subject, regions that process natural reinforcers become more sensitive to the drug than to the natural reinforcers (Garavan et al., 2000).

Acute intravenous cocaine given to cocaine abusers was shown to activate several regions (including BA 25, the insula, and the NAc) and deactivated others (amygdala and medial prefrontal cortex) (Breiter et al., 1997). Here, we compared the responses between cocaine-addicted and nonaddicted subjects for MP, which is pharmacologically similar to cocaine. As for intravenous cocaine, the response was not limited to prefrontal regions but included activation of the occipital cortex and cerebellum and deactivation of the amygdala, insula, and NAc. The decreases in the NAc and insula with MP contrasts with the increases reported with cocaine (Breiter et al., 1997). These discrepancies could reflect differences in subjects, drugs (cocaine vs MP; two doses vs one dose), and methods (PET vs functional MRI).

Imaging studies measuring DA increases in the striatum induced by amphetamine have also reported blunted responses in cocaine abusers compared with controls (Martinez et al., 2003). To our knowledge, such comparisons have not been made in the thalamus.

\section{Role of BA 25 and BA 11 in addiction}

The significant correlation between MP-induced activation of BA 25 and MP-induced desire for MP and cocaine craving suggests that its abnormal activation may underlie the intense desire to take the drug. Indeed, previous imaging studies in cocaine abusers have shown that activation of BA 25 after cocaine administration (Breiter et al., 1997) or after cocaine imagery (Kilts et al., 2001) was associated with cocaine craving.

BA 25 has been implicated in mediating the emotional responses to salient stimuli (rewarding as well as aversive). BA 25 is activated by natural and drug rewards (Breiter et al., 1997; Schlaepfer et al., 1998; Francis et al., 1999; Berns et al., 2001) and by positive and negative emotional stimuli (Elliott et al., 2000). The
Table 4. Location of regions where increases in metabolism induced by MP were increased significantly in cocaine-addicted subjects compared with controls $(p<$ 0.005 ; volume $\geq 100$ voxels)

\begin{tabular}{lllrrr}
\hline Region & Hemisphere & BA & \multicolumn{1}{l}{$x$} & \multicolumn{1}{l}{$y$} & \multicolumn{1}{l}{$z$} \\
\hline Frontal medial & Right & 11,25 & 17 & 33 & -16 \\
Occipital gyrus & Right & 19 & -37 & -47 & -5 \\
\hline
\end{tabular}

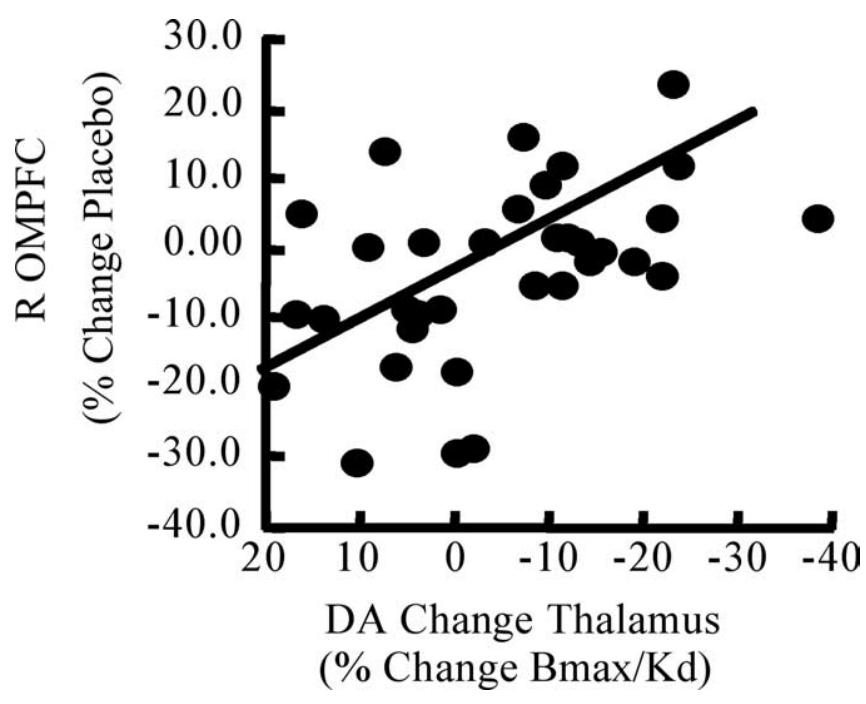

Figure 4. Correlation between MP-induced changes in OMPFC metabolism and the changes in thalamic DA. R OMPFC, Right OMPFC.

difference in the response of BA 25 between the groups is therefore consistent with an enhanced emotional response to MP in addicted subjects. Indeed, support for the role of BA 25 in emotional reactivity is its activation in cocaine abusers, not only by 
cocaine imagery but also by anger imagery (Kilts et al., 2001). The current study provides additional support by documenting an association between MP-induced changes in BA 25 and its changes in mood in the cocaine abusers.

The responses between groups also differed in BA 11 (medial OFC), which is a region involved with processing the reward value of stimuli and motivating behavioral responding to reward (Arana et al., 2003). Indeed, in rodents, lesions of the medial OFC impair cocaine-primed reinstatement (Fuchs et al., 2004). Thus, the difference between the groups in BA 11 is likely to reflect the enhanced saliency value of MP in cocaine-addicted subjects. Abnormalities in the lateral OFC have also been documented in cocaine-addicted subjects and have been linked to poor impulse control (Goldstein et al., 2001). This suggests that both the medial and lateral orbitofrontal cortices are involved in cocaine addiction.

BA 25 and BA 11 are likely to play complementary roles in addiction, with BA 25 processing the emotional reactivity to the drug and BA 11 processing the saliency value of the drug to the subject and the motivation to procure it. However, from the current data it is not possible to dissociate whether emotional reactivity reflects the enhanced saliency value of the drug or whether it is the enhanced emotional reactivity to the drug that increases the saliency value of the drug to the subject.

BA 25 and BA 11 have also been found to be activated by symptom provocation in patients with obsessive compulsive disorders (Breiter et al., 1996; Mataix-Cols et al., 2004). Thus, disruption of BA 25 and BA 11 may be a common substrate underlying disorders that manifest compulsive behaviors.

\section{Role of DA in the Thalamus and involvement in addiction}

The thalamus receives direct dopaminergic innervation (Melchitzky and Lewis, 2000). Therefore, the decreases in thalamic $\left[{ }^{11} \mathrm{C}\right]$ raclopride binding could reflect MP-induced blockade of DATs (Melchitzky and Lewis, 2000) or of norepinephrine transporters, because these transporters also participate in DA reuptake (Moron et al., 2002) and are densely concentrated in the thalamus (Melchitzky and Lewis, 2001).

The significant association between MP-induced thalamic DA changes and the OMPFC metabolic changes suggests that the mesothalamic DA projection regulates the responses of the OMPFC to MP. However, because the innervation is reciprocal, it is also possible that the OMPFC drives the MP-induced DA changes in the thalamus via direct (Cavada et al., 2000) or indirect (Rolls, 2004) projections. Indeed, in rodents, the prefrontal cortex can modulate the response of thalamic neurons to DA (Lavin and Grace, 1998; Cavada et al., 2000). Although there is limited information on the role of the thalamus in addiction, there is evidence of thalamic involvement in conditioned drug responses (McAlonan et al., 1993). For example, studies in rodents have shown differential involvement of the thalamus in contingent versus noncontingent administration of cocaine (Porrino et al., 2002) and on the responses to cocaine when given in a conditioned environment versus when given in the home cage (Knapp et al., 2002). Similarly, the thalamus was differentially activated by MP only when cocaine abusers expected to receive it but not when they did not expect to get it (Volkow et al., 2003). This expectation effect was also most likely attributable to conditioned responses.

Chronic cocaine can result in reorganization of DA input into the striatum and medial prefrontal cortex (for review, see Crombag et al., 2005). Adaptations in glutamatergic projection from the prefrontal cortex to the ventral striatum (including the NAc) are also critical for drug seeking in animal models of addiction (Kalivas and Volkow, 2005). The findings from the present study suggest that the mesothalamic DA pathway may be an additional component in the mesocorticostriatal circuit thought to be critical for drug seeking (Kalivas and Volkow, 2005). Preclinical studies support a functional relationship between the medial thalamus and mesocortico-accumbens circuitry in regulating behavioral activation. For example, inhibition of medial thalamic output to the prefrontal cortex results in locomotor activation, and the behavioral activation is associated with activation of mesocorticolimbic DA projections (Jones et al., 1988; Klitenick and Kalivas, 1994; Churchill et al., 1996). Also, activation of the medial thalamus stimulates the prefrontal cortex, as measured by c-fos staining (Bubser et al., 1997). Interestingly, inhibition of medial thalamic projections to the medial prefrontal cortex in rats disrupts working memory (Romanides et al., 1999), and deficits in higher cognitive function are thought to contribute to the decreased ability of addicts to control drug seeking and relapse (Berke and Hyman, 2000; Kalivas and Volkow, 2005).

\section{Limitations}

FDG measurements reflect the average activity over $30 \mathrm{~min}$ and thus may not be sensitive to short-lasting effects of MP. The limited spatial resolution of our PET scanner did not allow us to quantify $B_{\max } / K_{\mathrm{d}}$ changes in the NAc. The specific to nonspecific binding ratio for $\left[{ }^{11} \mathrm{C}\right]$ raclopride in the thalamus is low, so we cannot exclude the possibility that it reflects nonspecific effects.

The placebo was given on the first day, and MP was given on the second day. Thus, we cannot rule out the contribution of an order effect. However, this is unlikely to account for the differences between addicted subjects and controls.

Cocaine-addicted subjects and controls had very different experiences with stimulants, and we cannot rule out the possibility that in the addicted subjects the decreased high could reflect tolerance (cross-tolerance from cocaine) and that the increased desire for MP could reflect learned responses from previous experiences with stimulants. We also acknowledge that correlations do not necessarily reflect causal associations. Finally, we cannot determine whether differences in addicted subjects are caused by drug abuse or whether they preceded drug consumption.

\section{Summary}

The differential response to MP in right BA 25 (region implicated in emotional reactivity) and BA 11 (region implicated in saliency attribution and motivation), for controls and addicted subjects, implicates these brain regions as a critical neural substrate of addiction. They also suggest that the meso-thalamo-cortical circuit contributes to these processes.

\section{References}

Arana FS, Parkinson JA, Hinton E, Holland AJ, Owen AM, Roberts AC (2003) Dissociable contributions of the human amygdala and orbitofrontal cortex to incentive motivation and goal selection. J Neurosci 23:9632-9638.

Berke JD, Hyman SE (2000) Addiction, dopamine, and the molecular mechanisms of memory. Neuron 25:515-532.

Berns GS, McClure SM, Pagnoni G, Montague PR (2001) Predictability modulates human brain response to reward. J Neurosci 21:2793-2798.

Bolla KI, Eldreth DA, London ED, Kiehl KA, Mouratidis M, Contoreggi C, Matochik JA, Kurian V, Cadet JL, Kimes AS, Funderburk FR, Ernst M (2003) Orbitofrontal cortex dysfunction in abstinent cocaine abusers performing a decision-making task. NeuroImage 19:1085-1094.

Bonson KR, Grant SJ, Contoreggi CS, Links JM, Metcalfe J, Weyl HL, Kurian V, Ernst M, London ED (2002) Neural systems and cue-induced cocaine craving. Neuropsychopharmacology 26:376-386. 
Breiter HC, Rauch SL, Kwong KK, Baker JR, Weisskoff RM, Kennedy DN, Kendrick AD, Davis TL, Jiang A, Cohen MS, Stern CE, Belliveau JW, Baer L, O'Sullivan RL, Savage CR, Jenike MA, Rosen BR (1996) Functional magnetic resonance imaging of symptom provocation in obsessivecompulsive disorder. Arch Gen Psychiatry 53:595-606.

Breiter HC, Gollub RL, Weisskoff RM, Kennedy DN, Makris N, Berke JD, Goodman JM, Kantor HL, Gastfriend DR, Riorden JP, Mathew RT, Rosen BR, Hyman SE (1997) Acute effects of cocaine on human brain activity and emotion. Neuron 19:591-611.

Bubser M, Feenstra MG, Erdtsieck-Ernste EB, Botterblom MH, Van Uum HF, Pool CW (1997) Modulatory role of catecholamines in the transsynaptic expression of c-fos in the rat medial prefrontal cortex induced by disinhibition of the mediodorsal thalamus: a study employing microdialysis and immunohistochemistry. Brain Res 749:214-225.

Cavada C, Company T, Tejedor J, Cruz-Rizzolo RJ, Reinoso-Suarez F (2000) The anatomical connections of the macaque monkey orbitofrontal cortex. A review. Cereb Cortex 10:220-242.

Childress AR, Mozley PD, McElgin W, Fitzgerald J, Reivich M, O'Brien CP (1999) Limbic activation during cue-induced cocaine craving. Am J Psychiatry 156:11-18.

Churchill L, Zahm DS, Duffy P, Kalivas PW (1996) The mediodorsal nucleus of the thalamus in rats-II. Behavioral and neurochemical effects of GABA agonists. Neuroscience 70:103-112.

Collins L, Holmes C, Peters TM, Evans AC (1995) Automatic 3-D modelbased neuroanatomical segmentation. Hum Brain Mapp 3:190-208.

Crombag HS, Gorny G, Li Y, Kolb B, Robinson TE (2005) Opposite effects of amphetamine self-administration experience on dendritic spines in the medial and orbital prefrontal cortex. Cereb Cortex 15:341-348.

Dao-Castellana MH, Samson Y, Legault F, Martinot JL, Aubin HJ, Crouzel C, Feldman L, Barrucand D, Rancurel G, Feline A, Syrota A (1998) Frontal dysfunction in neurologically normal chronic alcoholic subjects: metabolic and neuropsychological findings. Psychol Med 28:1039-1048.

Dirckx SG, Risinger RC, Ross TJ, Stein EA (2004) Behavioral correlates of iv methylphenidate and cocaine in the human brain. Paper presented at 10th Annual Human Brain Mapping Meeting, Budapest, June.

Elliott R, Rubinsztein JS, Sahakian BJ, Dolan RJ (2000) Selective attention to emotional stimuli in a verbal go/no-go task: an fMRI study. NeuroReport 11:1739-1744.

Francis S, Rolls ET, Bowtell R, McGlone F, O'Doherty J, Browning A, Clare S, Smith E (1999) The representation of pleasant touch in the brain and its relationship with taste and olfactory areas. NeuroReport 10:453-459.

Franklin TR, Acton PD, Maldjian JA, Gray JD, Croft JR, Dackis CA, O’Brien CP, Childress AR (2002) Decreased gray matter concentration in the insular, orbitofrontal, cingulate, and temporal cortices of cocaine patients. Biol Psychiatry 51:134-142.

Friston KJHA, Worsley KJ, Poline JB, Frith CD, Frackowiak RSJ (1995) Statistical parametric maps in functional imaging: a general linear approach. Hum Brain Mapp 2:189-210.

Fuchs RA, Evans KA, Parker MP, See RE (2004) Differential involvement of orbitofrontal cortex subregions in conditioned cue-induced and cocaineprimed reinstatement of cocaine seeking in rats. J Neurosci 24:6600-6610.

Garavan H, Pankiewicz J, Bloom A, Cho JK, Sperry L, Ross TJ, Salmeron BJ, Risinger R, Kelley D, Stein EA (2000) Cue-induced cocaine craving: neuroanatomical specificity for drug users and drug stimuli. Am J Psychiatry 157:1789-1798.

Goldstein RZ, Volkow ND, Wang GJ, Fowler JS, Rajaram S (2001) Addiction changes orbitofrontal gyrus function: involvement in response inhibition. NeuroReport 12:2595-2599.

Grant S, London ED, Newlin DB, Villemagne VL, Liu X, Contoreggi C, Phillips RL, Kimes AS, Margolin A (1996) Activation of memory circuits during cue-elicited cocaine craving. Proc Natl Acad Sci USA 93:12040-12045.

Jones MW, Kilpatrick IC, Phillipson OT (1988) Dopamine function in the prefrontal cortex of the rat is sensitive to a reduction of tonic GABAmediated inhibition in the thalamic mediodorsal nucleus. Exp Brain Res 69:623-634.

Kalivas PW, Volkow ND (2005) The neurobiology of addiction: a pathology of motivation and choice. Am J Psychiatry, in press.

Kilts CD, Schweitzer JB, Quinn CK, Gross RE, Faber TL, Muhammad F, Ely TD, Hoffman JM, Drexler KP (2001) Neural activity related to drug craving in cocaine addiction. Arch Gen Psychiatry 58:334-341.
Klitenick MA, Kalivas PW (1994) Behavioral and neurochemical studies of opioid effects in the pedunculopontine nucleus and mediodorsal thalamus. J Pharmacol Exp Ther 269:437-448.

Knapp CM, Printseva B, Cottam N, Kornetsky C (2002) Effects of cue exposure on brain glucose utilization 8 days after repeated cocaine administration. Brain Res 950:119-126.

Koob GF, Bloom FE (1988) Cellular and molecular mechanisms of drug dependence. Science 242:715-723.

Lancaster JL, Rainey LH, Summerlin JL, Freitas CS, Fox PT, Evans AE, Toga AW, Maziotta JC (1997) Automated labeling of the human brain: a preliminary report on the development and evaluation of a forwardtransform method. Hum Brain Mapp 5:238-242.

Lancaster JL, Woldorff MG, Parsons LM, Liotti M, Freitas CS, Rainey L, Kochunov PV, Nickerson D, Mikiten SA, Fox PT (2000) Automated Talairach atlas labels for functional brain mapping. Hum Brain Mapp 10:120-131.

Lavin A, Grace AA (1998) Dopamine modulates the responsivity of mediodorsal thalamic cells recorded in vitro. J Neurosci 18:10566-10578.

Logan J, Fowler JS, Volkow ND, Wolf AP, Dewey SL, Schlyer DJ, MacGregor RR, Hitzemann R, Bendriem B, Gatley SJ, Wolf AP (1990) Graphical analysis of reversible radioligand binding from time-activity measurements applied to $\left[\mathrm{N}-{ }^{11} \mathrm{C}\right.$-methyl $]-(-)$-cocaine PET studies in human subjects. J Cereb Blood Flow Metab 10:740-747.

Logan J, Volkow ND, Fowler JS, Wang GJ, Dewey SL, MacGregor R, Schlyer D, Gatley SJ, Pappas N, King P, Wolf AP (1994) Effects of blood flow on $\left[{ }^{11} \mathrm{C}\right]$ raclopride binding in the brain: model simulations and kinetic analysis of PET data. J Cereb Blood Flow Metab 14:995-1010.

Ma Y, Volkow ND, Zhu W, Rao M, Pradhan K, Wang G-J (2004) Automated region of interest (ROI) analysis for PET studies. Paper presented at 10th Annual Human Brain Mapping Meeting, Budapest, June.

Maas LC, Lukas SE, Kaufman MJ, Weiss RD, Daniels SL, Rogers VW, Kukes TJ, Renshaw PF (1998) Functional magnetic resonance imaging of human brain activation during cue-induced cocaine craving. Am J Psychiatry 155:124-126.

Martinez D, Foltin RF, Kegeles L, Hwang, D, Huang Y, Hackett E, Frankle G, Laruelle M (2003) PET imaging of dopamine transmission in the striatal substructures of humans and predictors of relapse. Soc Neurosci Abstr 29:354.8.

Mataix-Cols D, Wooderson S, Lawrence N, Brammer MJ, Speckens A, Phillips ML (2004) Distinct neural correlates of washing, checking, and hoarding symptom dimensions in obsessive-compulsive disorder. Arch Gen Psychiatry 61:564-576.

Matochik JA, London ED, Eldreth DA, Cadet JL, Bolla KI (2003) Frontal cortical tissue composition in abstinent cocaine abusers: a magnetic resonance imaging study. NeuroImage 19:1095-1102.

McAlonan GM, Robbins TW, Everitt BJ (1993) Effects of medial dorsal thalamic and ventral pallidal lesions on the acquisition of a conditioned place preference: further evidence for the involvement of the ventral striatopallidal system in reward-related processes. Neuroscience 52:605-620.

Melchitzky DS, Lewis DA (2000) Tyrosine hydroxylase- and dopamine transporter-immunoreactive axons in the primate cerebellum. Evidence for a lobular- and laminar-specific dopamine innervation. Neuropsychopharmacology 22:466-472.

Melchitzky DS, Lewis DA (2001) Dopamine transporter-immunoreactive axons in the mediodorsal thalamic nucleus of the macaque monkey. Neuroscience 103:1033-1042.

Modell JG, Mountz JM, Beresford TP (1990) Basal ganglia/limbic striatal and thalamocortical involvement in craving and loss of control in alcoholism. J Neuropsychiatry Clin Neurosci 2:123-144.

Moron JA, Brockington A, Wise RA, Rocha BA, Hope BT (2002) Dopamine uptake through the norepinephrine transporter in brain regions with low levels of the dopamine transporter: evidence from knock-out mouse lines. J Neurosci 22:389-395.

Myrick H, Anton RF, Li X, Henderson S, Drobes D, Voronin K, George MS (2004) Differential brain activity in alcoholics and social drinkers to alcohol cues: relationship to craving. Neuropsychopharmacology 29:393-402.

Ongur D, Price JL (2000) The organization of networks within the orbital and medial prefrontal cortex of rats, monkeys and humans. Cereb Cortex 10:206-219.

Porrino LJ, Lyons D, Miller MD, Smith HR, Friedman DP, Daunais JB, Nader MA (2002) Metabolic mapping of the effects of cocaine during the ini- 
tial phases of self-administration in the nonhuman primate. J Neurosci 22:7687-7694.

Rolls ET (2004) The functions of the orbitofrontal cortex. Brain Cogn 55:11-29.

Romanides AJ, Duffy P, Kalivas PW (1999) Glutamatergic and dopaminergic afferents to the prefrontal cortex regulate spatial working memory in rats. Neuroscience 92:97-106.

Schlaepfer TE, Strain EC, Greenberg BD, Preston KL, Lancaster E, Bigelow GE, Barta PE, Pearlson GD (1998) Site of opioid action in the human brain: mu and kappa agonists' subjective and cerebral blood flow effects. Am J Psychiatry 155:470-473.

Sekine Y, Minabe Y, Ouchi Y, Takei N, Iyo M, Nakamura K, Suzuki K, Tsukada H, Okada H, Yoshikawa E, Futatsubashi M, Mori N (2003) Association of dopamine transporter loss in the orbitofrontal and dorsolateral prefrontal cortices with methamphetamine-related psychiatric symptoms. Am J Psychiatry 160:1699-1701.

Sell LA, Morris JS, Bearn J, Frackowiak RS, Friston KJ, Dolan RJ (2000) Neural responses associated with cue evoked emotional states and heroin in opiate addicts. Drug Alcohol Depend 60:207-216.

Sokoloff L, Reivich M, Kennedy C, Des Rosiers MH, Patlak CS, Pettigrew KD, Sakurada O, Shinohara M (1977) The $\left[{ }^{14} \mathrm{C}\right]$ deoxyglucose method for the measurement of local cerebral glucose utilization: theory, procedure, and normal values in the conscious and anesthetized albino rat. J Neurochem 28:897-916.

Srinivas NR, Hubbard JW, Quinn D, Korchinski ED, Midha KK (1991) Extensive and enantioselective presystemic metabolism of DL-threomethylphenidate in humans. Prog Neuropsychopharmacol Biol Psychiatry 15:213-220.

Talairach J, Tournoux P (1988) Co-planar stereotaxic atlas of the human brain. New York: Thieme Medical Publishers.

Volkow ND, Fowler JS (2000) Addiction, a disease of compulsion and drive: involvement of the orbitofrontal cortex. Cereb Cortex 10:318-325.

Volkow ND, Fowler JS, Wolf AP, Hitzemann R, Dewey S, Bendriem B, Alpert R, Hoff A (1991) Changes in brain glucose metabolism in cocaine dependence and withdrawal. Am J Psychiatry 148:621-626.

Volkow ND, Fowler JS, Wang GJ, Hitzemann R, Logan J, Schlyer DJ, Dewey SL, Wolf AP (1993) Decreased dopamine D2 receptor availability is associated with reduced frontal metabolism in cocaine abusers. Synapse 14:169-177.

Volkow ND, Wang GJ, Fowler JS, Logan J, Schlyer D, Hitzemann R, Lieberman J, Angrist B, Pappas N, MacGregor R (1994) Imaging endogenous dopamine competition with $\left[{ }^{11} \mathrm{C}\right]$ raclopride in the human brain. Synapse 16:255-262.

Volkow ND, Ding YS, Fowler JS, Wang GJ, Logan J, Gatley JS, Dewey S, Ashby C, Liebermann J, Hitzemann R, Wolf AP (1995) Is methylphenidate like cocaine? Studies on their pharmacokinetics and distribution in the human brain. Arch Gen Psychiatry 52:456-463.
Volkow ND, Gillespie H, Mullani N, Tancredi L, Grant C, Valentine A, Hollister L (1996) Brain glucose metabolism in chronic marijuana users at baseline and during marijuana intoxication. Psychiatry Res 67:29-38.

Volkow ND, Wang GJ, Fowler JS, Logan J, Gatley SJ, Hitzemann R, Chen AD, Dewey SL, Pappas N (1997a) Decreased striatal dopaminergic responsiveness in detoxified cocaine-dependent subjects. Nature 386:830-833.

Volkow ND, Wang GJ, Fowler JS, Logan J, Angrist B, Hitzemann R, Lieberman J, Pappas N (1997b) Effects of methylphenidate on regional brain glucose metabolism in humans: relationship to dopamine D2 receptors. Am J Psychiatry 154:50-55.

Volkow ND, Wang GJ, Overall JE, Hitzemann R, Fowler JS, Pappas N, Frecska E, Piscani K (1997c) Regional brain metabolic response to lorazepam in alcoholics during early and late alcohol detoxification. Alcohol Clin Exp Res 21:1278-1284.

Volkow ND, Wang GJ, Fowler JS, Hitzemann R, Angrist B, Gatley SJ, Logan J, Ding YS, Pappas N (1999) Association of methylphenidate-induced craving with changes in right striato-orbitofrontal metabolism in cocaine abusers: implications in addiction. Am J Psychiatry 156:19-26.

Volkow ND, Chang L, Wang GJ, Fowler JS, Ding YS, Sedler M, Logan J, Franceschi D, Gatley J, Hitzemann R, Gifford A, Wong C, Pappas N (2001) Low level of brain dopamine D2 receptors in methamphetamine abusers: association with metabolism in the orbitofrontal cortex. Am J Psychiatry 158:2015-2021.

Volkow ND, Zhu W, Felder CA, Mueller K, Welsh TF, Wang GJ, de Leon MJ (2002) Changes in brain functional homogeneity in subjects with Alzheimer's disease. Psychiatry Res 114:39-50.

Volkow ND, Wang GJ, Ma Y, Fowler JS, Zhu W, Maynard L, Telang F, Vaska P, Ding YS, Wong C, Swanson JM (2003) Expectation enhances the regional brain metabolic and the reinforcing effects of stimulants in cocaine abusers. J Neurosci 23:11461-11468.

Wang GJ, Volkow ND, Roque CT, Cestaro VL, Hitzemann RJ, Cantos EL, Levy AV, Dhawan AP (1993) Functional importance of ventricular enlargement and cortical atrophy in healthy subjects and alcoholics as assessed with PET, MR imaging, and neuropsychologic testing. Radiology 186:59-65.

Wang GJ, Volkow ND, Hitzemann RJ, Wong C, Angrist B, Burr G, Pascani K, Pappas N, Lu A, Cooper T, Lieberman JA (1997) Behavioral and cardiovascular effects of intravenous methylphenidate in normal subjects and cocaine abusers. Eur Addiction Res 3:49-54.

Wang GJ, Volkow ND, Fowler JS, Cervany P, Hitzemann RJ, Pappas NR, Wong CT, Felder C (1999) Regional brain metabolic activation during craving elicited by recall of previous drug experiences. Life Sci 64:775-784.

Wexler BE, Gottschalk CH, Fulbright RK, Prohovnik I, Lacadie CM, Rounsaville BJ, Gore JC (2001) Functional magnetic resonance imaging of cocaine craving. Am J Psychiatry 158:86-95. 